\title{
SOMBREAMENTO DE PLANTAS DE Catharanthus roseus (L.) G. Don 'Pacifica White' POR MALHAS COLORIDAS: DESENVOLVIMENTO VEGETATIVO ${ }^{1}$
}

\author{
Shading of 'Pacifica White' Catharanthus roseus (L.) G. Don plants \\ with colored nets: vegetative development
}

\author{
Anderson Adriano Martins Melo², Amauri Alves de Alvarenga ${ }^{3}$
}

\begin{abstract}
RESUMO
As malhas coloridas têm sido utilizadas para manipular o desenvolvimento vegetativo, melhorando a utilização da radiação solar por plantas ornamentais. Objetivou-se, neste trabalho estudar o efeito da redução de $50 \%$ da radiação fotossinteticamente ativa sobre o crescimento vegetativo de plantas de Catharanthus roseus (L.) G. Don, por meio de malhas azul e vermelha e malha preta, em comparação com plantas crescidas na ausência de sombreamento (pleno sol). As plantas foram obtidas a partir de sementes e tratadas por 180 dias. Foram avaliados o ganho de biomassa e a distribuição de matéria seca nas plantas, o conteúdo de pigmentos foliares (clorofilas e carotenóides) e de nitrogênio foliar. A malha vermelha provocou um aumento de matéria seca total e de área foliar das plantas em comparação com as malhas azul, preta e ao tratamento a pleno sol, porém, exceto em relação a esse tratamento, a malha vermelha causou menor conteúdo de nitrogênio e pigmentos foliares. A maior relação raiz/parte aérea e relação clorofila $\mathrm{a} / \mathrm{b}$, menores razões de área foliar e de massa foliar das plantas crescidas a pleno sol em relação às plantas sombreadas indicam um efeito mais proeminente da irradiância mais alta do que da alteração do espectro de luz. O sombreamento altera significativamente a distribuição de matéria seca e o uso de malhas de diferentes cores modifica o conteúdo de pigmentos fotossintéticos dessa espécie.
\end{abstract}

Termos para indexação: Vinca, área foliar, distribuição espectral, matéria seca, carotenóides, clorofilas, Catharanthus roseus.

\begin{abstract}
Colored shade nets have been used to manipulate the vegetative development, improving the utilization of solar radiation by ornamental plants. This work aimed to study the effect of 50\% reduction of PAR on vegetative growth of plants of Catharanthus roseus (L.) G. Don, using blue and red nets, and black net, in comparison to plants growing under full sunlight (lack of shading). The plants were obtained from seeds and treated for 180 days. Biomass increment and distribution, pigment content (chlorophylls and carotenoids) and foliar nitrogen were evaluated. The red net caused an increase of total dry mass and total leaf area of plants when compared to the blue net, black net and the full sunlight treatment, however, except in relation to the last treatment, the red net caused lower contents of foliar nitrogen and pigments. The higher root/stem and chlorophyll a/b ratios and the lower leaf area and leaf dry mass of plants growing under full sunlight in relation to shaded plants indicate a more prominent effect of the higher irradiance than the spectral alteration. Shading alters significantly the dry matter distribution and the use of shade nets of different colors affects the content of photosynthetic pigments of this species.
\end{abstract}

Index terms: Vinca, leaf area, spectral distribution, dry matter, carotenoids, chlorophylls, Catharanthus roseus.

(Recebido em 28 de setembro de 2006 e aprovado em 6 de março de 2008)

\section{INTRODUÇÃO}

A vinca [Catharanthus roseus (L.) G. Don] é uma das plantas medicinais mais extensivamente estudadas. Além de planta ornamental, sua importância se deve à produção e acúmulo de alcalóides bisindólicos nas folhas (vimblastina e vincristina), utilizados no tratamento de diversas formas de câncer. No entanto, há poucos relatos na literatura sobre o desenvolvimento dessa espécie em relação às variações de fatores do ambiente.
As plantas, organismos autótrofos e sésseis, dependem da energia radiante para sua sobrevivência e competição em comunidades vegetais, devendo para isso, adaptar o seu crescimento e desenvolvimento à radiação disponível no ambiente (FRANKLIN \& WHITELAM, 2005).

Muitos trabalhos têm demonstrado que a qualidade da luz influencia muitos aspectos do desenvolvimento de plantas, como o conteúdo de nitrogênio e pigmentos foliares e a partição de biomassa entre folhas, caules e raízes (PONS \& BERKEL, 2004; RAJAPAKSE \& KELLY,

\footnotetext{
${ }^{1}$ Parte da dissertação do primeiro autor

Engenheiro Agrônomo, Doutorando em Fisiologia Vegetal - Departamento de Biologia Vegetal/DBV - Universidade Federal de Viçosa/UFV - Avenida P.H. Rolfs, s/n - 36570-000 - Viçosa, MG - melo.anderson@yahoo.com.br

${ }^{3}$ Engenheiro Agrônomo, Doutor, Professor Titular - Departamento de Biologia/DBI - Universidade Federal de Lavras/UFLA - Cx. P. 3037 - $37200-000$ Lavras, MG - amauriaa@ufla.br
}

Ciênc. agrotec., Lavras, v. 33, n. 2, p. 514-520, mar./abr., 2009 
1992). A qualidade da luz pode causar alterações no fotoequilíbrio do fitocromo, relacionado às quantidades relativas das formas Fv e Fvd e, assim, determinar uma razão Fvd/Ftotal de cuja percepção dependem muitas respostas morfogênicas (KASPERBAUER \& PEASLEE, 1973; SMITH \& WHITELAM, 1997).

As plantas podem perceber mudanças sutis na composição de vermelho e vermelho-distante do ambiente em que se encontram, ajustando-se morfológica e fisiologicamente por meio do fitocromo (LI et al., 2000). A relação vermelho/ vermelho-distante (V/VD) é considerada um fator importante para respostas mediadas pelo fitocromo (BATSCHAUER, 1998). Em resposta aos sinais de baixa relação V/VD, muitas plantas mostram um rápido e pronunciado aumento na taxa de alongamento de caules e pecíolos, freqüentemente às expensas do desenvolvimento de folhas e órgãos de armazenamento (FRANKLIN \& WHITELAM, 2005).

A manipulação espectral da radiação natural tem sido utilizada em casas de vegetação com uso de filtros fotosseletivos líquidos, contendo sulfato de cobre (MCMAHON \& KELLY, 1995; RAJAPAKSE \& KELLY, 1992; RAJAPAKSE et al., 1999), ou por meio de coberturas coloridas, as quais modificam especificamente a luz nas regiões espectrais do ultravioleta, do visível ou do vermelho-distante, aumentando a quantidade de luz difusa em seu interior (OREN-SHAMIR et al., 2001; SHAHAK et al., 2004). A malha azul, diferentemente da vermelha, não reduz a razão V/VD do espectro da luz difusa, mas eleva levemente essa relação (SHAHAK et al., 2004). Seu efeito mais proeminente, segundo os autores, é aumentar a relação azul/vermelho na luz difusa em seu ambiente.

Segundo Oren-Shamir et al. (2001), que utilizaram malhas coloridas, e mediram a distribuição espectral da luz, sob malha azul, há transmissão de luz em uma banda abrangente em $470 \mathrm{~nm}$, além de outros picos na região do vermelho-distante e infravermelho (acima de $750 \mathrm{~nm}$ ), enquanto a vermelha tem maior transmitância em comprimentos de onda acima de $590 \mathrm{~nm}$ e um pico menor em torno de $400 \mathrm{~nm}$.

Objetivou-se, neste trabalho, avaliar o efeito da radiação solar alterada por coberturas de malhas de cor azul e vermelha sobre aspectos do desenvolvimento vegetativo de plantas de vinca.

\section{MATERIAIS E MÉTODOS}

O trabalho foi conduzido no período de novembro de 2005 a maio de 2006, no Setor de Fisiologia Vegetal, Departamento de Biologia da Universidade Federal de Lavras (UFLA), no município de Lavras, MG, a 918 m de altitude, $21^{\circ} 14^{\prime} \mathrm{S}$ e $45^{\circ} 00^{\prime} \mathrm{W}$.
Sementes de $C$. roseus cv. Pacifica White foram previamente embebidas em solução de $\mathrm{GA}_{3}\left(1 \mathrm{~g}\right.$.L $\left.\mathrm{L}^{-1}\right)$, por 24 horas para aumentar a germinabilidade e uniformidade da germinação. Em seguida, foram secas em papel absorvente, desinfestadas por $15 \mathrm{~min}$ em solução de Cercobin $^{\circledR}\left(1\right.$ g.L g $\left.^{-1}\right)$ e colocadas para germinar em caixas tipo Gerbox ${ }^{\circledR}$, sobre duas camadas de papel mata-borrão, em câmara de germinação tipo BOD sob temperatura de $23^{\circ} \mathrm{C}$ constante e no escuro. Após 3 dias, as sementes prégerminadas foram então transplantadas para tubetes com capacidade para $50 \mathrm{~cm}^{3}$, contendo substrato Plantmax ${ }^{\circledR} \mathrm{e}$ colocadas em viveiro com $70 \%$ de sombreamento (malha preta). Plântulas com $8 \mathrm{~cm}$ de altura, na parte aérea, e com dois pares de folhas verdadeiras (35 dias após emergência) foram selecionadas e transplantadas para o substrato definitivo, em colunas de PVC ( $20 \mathrm{~cm}$ de diâmetro e $20 \mathrm{~cm}$ de altura), contendo 5,0 L de terra de subsolo, areia e esterco bovino na proporção de 2:1:1. No solo utilizado foi feita análise do solo completa (macro e micronutrientes) no Departamento de Ciência do Solo da UFLA. Após análise do solo utilizado, foi preparada uma solução nutritiva visando corrigir deficiências nutricionais e suprir a planta, durante o período experimental. A aplicação foi feita apenas uma vez, após a transferência das plantas, com uso de proveta.

Os tratamentos de sombreamento consistiram de duas coberturas por malhas coloridas (vermelha e azul Polysack Plastic Industries ${ }^{\circledR}$ ), e uma preta, as quais, segundo o fabricante, possuem uma densidade da malha que fornece $50 \%$ de transmitância na região fotossinteticamente ativa, além de um tratamento testemunha a pleno sol. As malhas de diferentes cores, segundo o fabricante, alteram o espectro de luz solar por elas transmitida: a malha vermelha reduz as ondas azuis, verdes e amarelas, e acrescenta ondas na região do vermelho e vermelho-distante. A malha azul reduz a passagem de comprimentos de onda na faixa da luz do vermelho e do vermelho-distante, e aumenta a transmitância de comprimentos de onda na faixa de luz azul do espectro.

As plantas permaneceram sob os tratamentos por 180 dias, sendo irrigadas em intervalos de 2 dias. Após esse período, foi feita medição da área foliar, em 6 plantas em todas as folhas completamente expandidas, com Medidor Eletrônico de Área Foliar (LI-COR - LI-3100). Folhas, ramos e raízes, foram acondicionados em sacos de papel e transferidos para uma estufa com circulação forçada de ar a $50^{\circ} \mathrm{C}$. Após a secagem completa, por um período de 72 horas, os materiais foram pesados em balança analítica. Após a determinação da matéria seca, as folhas foram 
trituradas para a quantificação do nitrogênio foliar pelo método de Micro-kjeldahl (MA \& ZUAZAGA, 1942).

Alguns índices fisiológicos de crescimento foram avaliados, como razão de área foliar, razão de massa foliar e área foliar específica (RAF, RPF e AFE, respectivamente), por meio dos valores instantâneos de área foliar (A), expressos em $\mathrm{dm}^{2}$, matéria seca da planta $(\mathrm{P})$ e matéria seca das folhas (Pf), ambos expressos em $\mathrm{g}$, de acordo com Benincasa (1988).

Para análise do teor de clorofilas, foram extraídos $0,1 \mathrm{~g}$ de discos foliares de 3 folhas completamente expandidas por repetição, os quais foram macerados em gral, e o extrato diluído em um volume de $30 \mathrm{~mL}$ de acetona $80 \%$. As absorbâncias foram lidas em espectrofotômetro (Beckman - DU 640) e as quantificações da clorofila a, b e total realizadas segundo metodologia descrita por Arnon (1949).

A extração e a quantificação dos carotenóides totais foram realizadas em cinco folhas completamente expandidas por repetição, segundo a metodologia descrita por Duke \& Kenyon (1986). A concentração de carotenóides totais foi calculada com uso dos coeficientes de extinção molar de Sandmann \& Böger (1983) para o ß caroteno.

Este experimento foi conduzido em um delineamento experimental inteiramente casualizado (DIC), com 4 tratamentos de radiação (malha vermelha, azul, preta e pleno sol) e em 4 repetições (cada uma contendo 3 folhas para análise de clorofilas e 5 folhas para a análise de carotenóides). Para a análise de crescimento, o delineamento consistiu de quatro tratamentos de radiação e 6 repetições, sendo cada repetição constituída de uma planta. Todos os dados obtidos foram submetidos à análise de variância. As médias, quando significativas, foram submetidas ao teste de Tukey, em nível de $5 \%$ de probabilidade.

\section{RESULTADOS E DISCUSSÃO}

A matéria seca total das plantas de $C$. roseus foi significativamente afetada pelo uso de malhas coloridas (FIGURA 1 A). Observou-se que plantas cultivadas sob malha vermelha apresentaram maior teor de matéria seca total, em relação aos demais tratamentos. Esse tratamento também determinou maior acúmulo de matéria seca em caules, em relação aos tratamentos com malha preta e azul. $\mathrm{O}$ acúmulo de matéria seca foliar foi afetado pelo uso de sombreamento, sendo significativamente menor no tratamento a pleno sol, no qual se observa um maior incremento de matéria seca nas raízes em relação aos tratamentos com malha azul e preta.
Os maiores conteúdos de matéria seca total e de parte aérea, encontrados nas plantas sob malha vermelha em relação às demais, podem ter sido ocasionados pela menor relação V/VD, proporcionada por esse tratamento. Esse aumento da relação V/VD proporcionada pelos filtros pode ser um estímulo para uma maior conversão do fitocromo da forma ativa $(\mathrm{Fvd})$ para a forma inativa $(\mathrm{Fv})$, reduzindo a relação Fvd/Ftotal, o que causaria um maior alongamento de caules (MORGAN \& SMITH, 1978). Neste trabalho, o maior incremento de matéria seca da parte aérea no tratamento sob malha vermelha pode ser devido à menor relação V/VD, proporcionada por esse tratamento. Rajapakse \& Kelly (1992), utilizando filtros contendo soluções de sulfato de cobre, nas concentrações de $4 \%$ e $8 \%$, observaram aumento da relação V/VD da luz por eles transmitida, o que causou redução no conteúdo de matéria seca da parte aérea em relação ao controle (água destilada preenchendo o filtro).
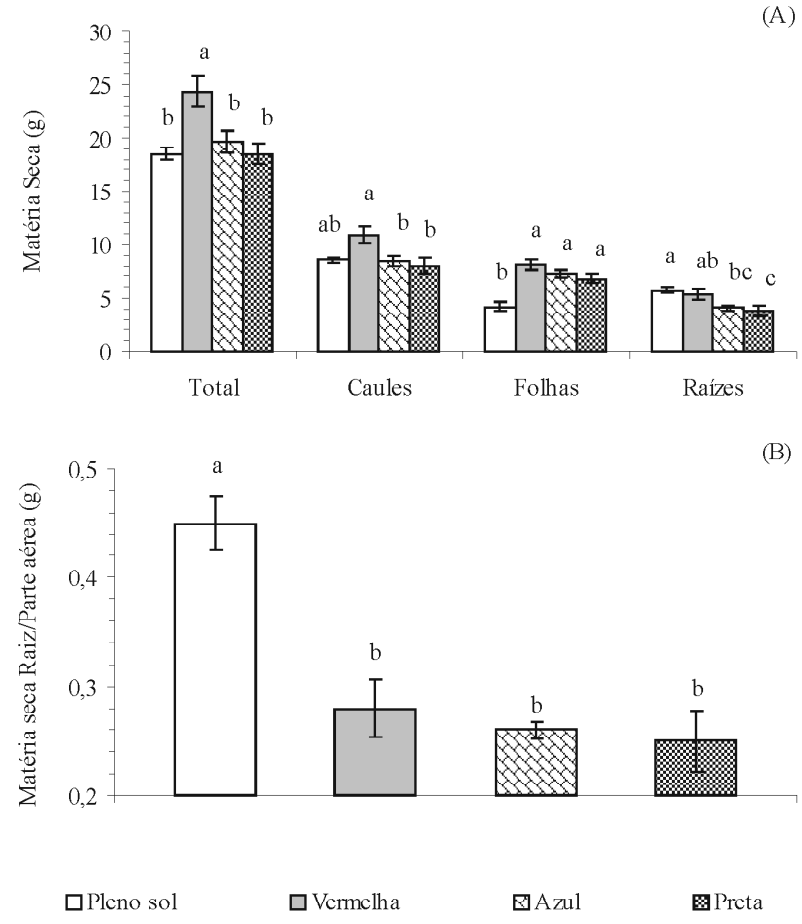

Figura 1 - Matéria seca total e particionada (A) e relação raiz/parte aérea (B) (g) de plantas de Catharanthus roseus cv. 'Pacifica White' submetidas ao sombreamento sob telados com malhas de diferentes cores e a pleno sol, durante 180 dias. Linhas verticais representam o erro padrão entre as médias $(n=6)$. Médias seguidas da mesma letra não diferem significativamente entre si, pelo teste de Tukey, a $5 \%$ de probabilidade. 
Analisando-se a distribuição de biomassa entre os diferentes órgãos da planta (FIGURA 2), verifica-se que grande parte dos fotoassimilados foi alocada nas raízes de plantas a pleno sol (31\%), em detrimento do investimento em folhas $(22,5 \%)$, o que determinou uma maior relação raiz/parte aérea para o tratamento a pleno sol (FIGURA 1 B). Os tratamentos com sombreamento não afetaram significativamente a distribuição de biomassa. Desse modo, parece que o efeito da irradiância é mais proeminente do que a alteração espectral sobre essa variável na espécie estudada.

A distribuição de matéria seca entre os diferentes órgãos de uma planta constitui um comportamento inerente às espécies vegetais e reflete a sua adaptabilidade às diferentes condições do ambiente (BENINCASA, 1988). Ainda não estão bem caracterizados os fatores que alteram alocação de biomassa entre os órgãos da planta em resposta às alterações espectrais. Alguns estudos, no entanto, associam a percepção do sinal ambiental pelo fitocromo e receptores de luz azul (criptocromos e fototropinas) à resposta de crescimento de caules em Arabidopsis, atribuindo-lhes uma ação coordenada (PARKS et al., 2001).

Segundo Colon-Carmona et al. (2000), existe participação de genes, cujas ações são mediadas por fotorreceptores, que modificam as relações entre reguladores de crescimento, alterando o balanço de auxinas, giberelinas e citocininas em resposta às modificações espectrais, o que poderia modificar a distribuição de fotoassimilados.

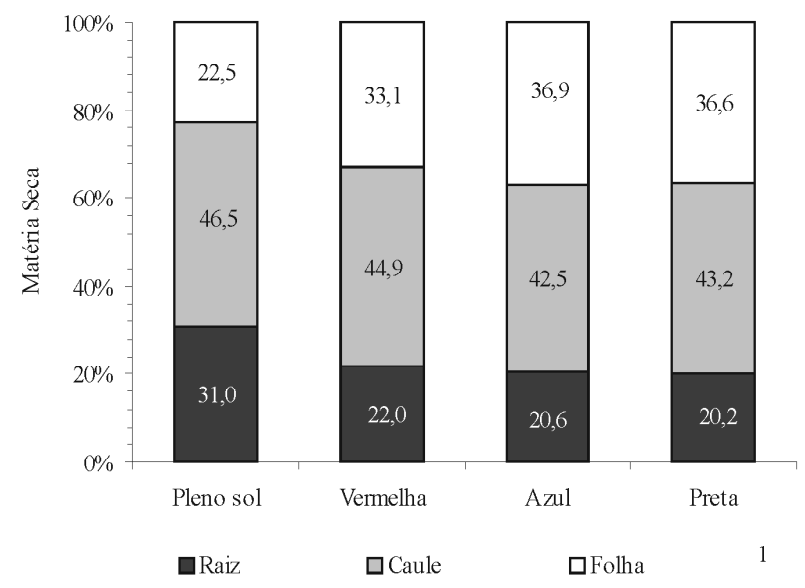

Figura 2 - Distribuição de matéria seca (g) entre os diferentes órgãos de plantas de Catharanthus roseus cv. 'Pacifica White', submetidas a sombreamento sob telados com malhas de diferentes cores e a pleno sol, durante 180 dias.
O uso de malhas preta e azul aumentou significativamente o conteúdo de nitrogênio foliar, comparativamente às demais (FIGURA 3 ). O tratamento com malha vermelha determinou maior conteúdo de nitrogênio foliar quando comparado às plantas cultivadas a pleno sol, as quais apresentaram também o menor conteúdo de matéria seca retida em folhas entre todos os tratamentos (FIGURA 1 A e FIGURA 2).

Esses resultados concordam com o observado por Dias-Filho (1999) e Evans \& Poorter (2001), que verificaram maior conteúdo de nitrogênio total em folhas de dicotiledôneas submetidas a uma menor irradiância. Pons $\&$ Berkel (2004) verificaram que o tratamento de seis espécies de plantas com luz vermelho-distante suplementar reduziu o conteúdo de nitrogênio, por área foliar em cinco dessas plantas. Os resultados aqui apresentados, em unidade de massa, podem ser atribuídos à provável menor razão V/VD sob a malha vermelha, em que as plantas apresentaram maior área foliar em relação às demais.

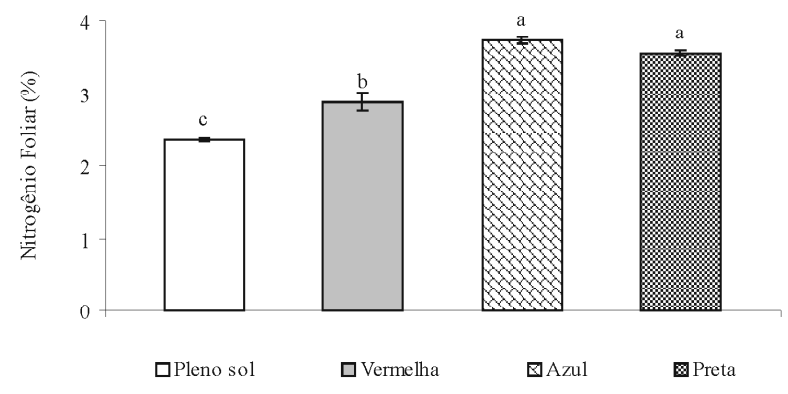

Figura 3 - Conteúdo de nitrogênio total (g. $\mathrm{g}^{-1}$ de massa seca foliar) de folhas de plantas de Catharanthus roseus cv. 'Pacifica White', submetidas ao sombreamento sob telados com malhas de diferentes cores e a pleno sol, durante 180 dias. Linhas verticais representam o erro padrão entre as médias $(n=4)$. Médias seguidas da mesma letra não diferem significativamente entre si, pelo teste de Tukey, a $5 \%$ de probabilidade.

A área foliar foi significativamente afetada pelo sombreamento (FIGURA 4 A). As plantas sob malha vermelha exibiram maior superfície total, seguidas daquelas sob o tratamento com malha azul. As plantas cultivadas a pleno sol tiveram uma área foliar significativamente reduzida e menor RAF e RPF em relação aos tratamentos de sombreamento (FIGURA 4 B), fato que pode ser correlacionado ao menor teor de matéria seca total dessas plantas.

A ocorrência de menor RPF e RAF, bem como maior relação raiz/parte aérea nas plantas a pleno sol quando 
comparadas àquelas sombreadas, pode estar relacionada a uma plasticidade anatômica induzida por estresse, resultando na inadaptabilidade das plantas dessa cultivar ao regime de maior irradiância.

Muitas respostas morfogênicas em plantas se devem à percepção da razão entre o conteúdo de fitocromo vermelho-distante (Fvd) e o total deste fotorreceptor (Ftotal). A razão Fvd/Ftotal é reduzida sob radiação na região do vermelho-distante (KASPERBAUER \& PEASLEE, 1973; SMITH \& WHITELAM, 1997). Desse modo, a razão V/VD e a taxa de fluência percebida pelas plantas constituem sinais ecofisiológicos que sinalizam acerca da proximidade entre elas e induz, em cada uma, às alterações na morfologia e na alocação de assimilados (BALLARÉ et al., 1992).
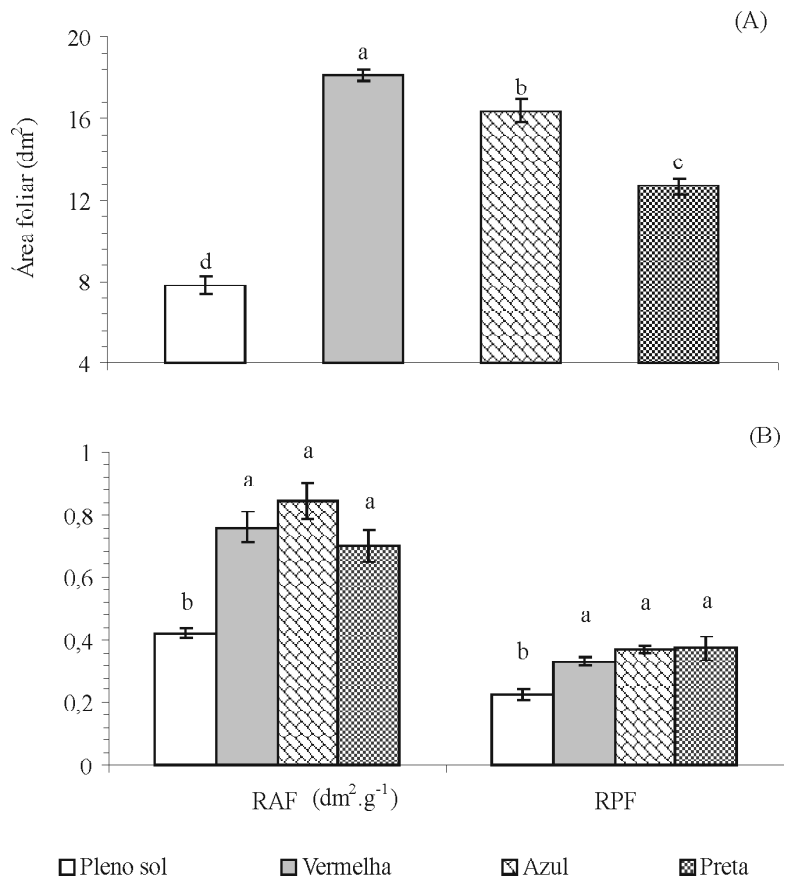

Figura 4 - Área foliar total (A) e Razão de área foliar (RAF) $\left(\mathrm{dm}^{2} \cdot \mathrm{g}^{-1}\right)$ e Razão de peso foliar (RPF) (B) de plantas de Catharanthus roseus cv. 'Pacifica White', submetidas ao sombreamento sob telados com malhas de diferentes cores e a pleno sol, durante 180 dias. Linhas verticais representam o erro padrão entre as médias $(n=6)$. Médias seguidas da mesma letra não diferem significativamente entre si, pelo teste de Tukey, a $5 \%$ de probabilidade.

Os teores de clorofila total foram semelhantes nas plantas sob os tratamentos com malha azul e preta, (FIGURA $5 \mathrm{~A}$ ), em relação ao tratamento com malha vermelha ou a pleno sol, no qual se observou menor teor de clorofila total em relação aos demais tratamentos.

Kasperbauer \& Peaslee (1973), também observaram menor conteúdo de clorofila por unidade de área foliar em tabaco, que receberam menor relação V/VD. Os resultados aqui observados podem ser atribuídos a uma provável menor relação V/VD existente no ambiente proporcionado pela malha vermelha. McMahon \& Kelly (1995) analisaram plantas de crisântemo sob filtro de policarbonato contendo sulfato de cobre líquido (que reduz a transmissão da luz vermelho-distante). Esses autores observaram maiores teores de clorofila a, clorofila b, carotenóides totais e plantas com menor porte, porém menor área foliar, em comparação ao controle (filtro contendo água) ou sob filtro com tinta azul, com uma relação V/VD menor.

Apesar de haver um menor teor de clorofila total nas plantas sob tratamento a pleno sol, esse apresentou maior relação clorofila a/b que os demais tratamentos. A relação clorofila $a / b$, provavelmente, foi reduzida como função da menor irradiância experimentada pelos tratamentos sob malhas. Folhas adaptadas a ambientes sombreados necessitam de menor quantidade de clorofilas $b$, que absorvem radiação ligeiramente mais energética que clorofilas a. Esse fenômeno é consistente com outros trabalhos, sendo atribuído também ao aumento do conteúdo de clorofila b pelo complexo de clorofilas do fotossistema II, em plantas sob alta irradiância (ANDERSON et al., 1995).

Os resultados indicam uma predominância do efeito da intensidade luminosa sobre a razão V/VD ou mesmo da maior relação azul/vermelho proporcionada pela malha azul sobre a razão clorofila a/b, o que está de acordo os dados de Pons \& Berkel (2004), sobre folhas de seis diferentes espécies de plantas. Esses efeitos indicam que o aparato fotossintetizante foi capaz de se ajustar à alteração espectral da radiação, mas não às diferentes irradiâncias impostas às plantas.

Plantas cultivadas a pleno sol mostraram-se amareladas, de porte baixo. Os baixos conteúdos de clorofilas e carotenóides totais, nitrogênio foliar e área foliar dessas plantas parecem indicar ocorrência de fotoinibição nas plantas sob esse regime de radiação. Segundo Edreva (2005), a fotoinibição pode ser provocada por elevada irradiância e conseqüiente superprodução de elétrons, o que leva à formação de espécies altamente reativas de oxigênio no PSII, causando a desestruturação de membranas e destruição dos cloroplastos. O baixo conteúdo de carotenóides, nas folhas das plantas a pleno sol, pode estar associado a uma proteção insuficiente dos complexos coletores de luz dos fotossistemas nesse 

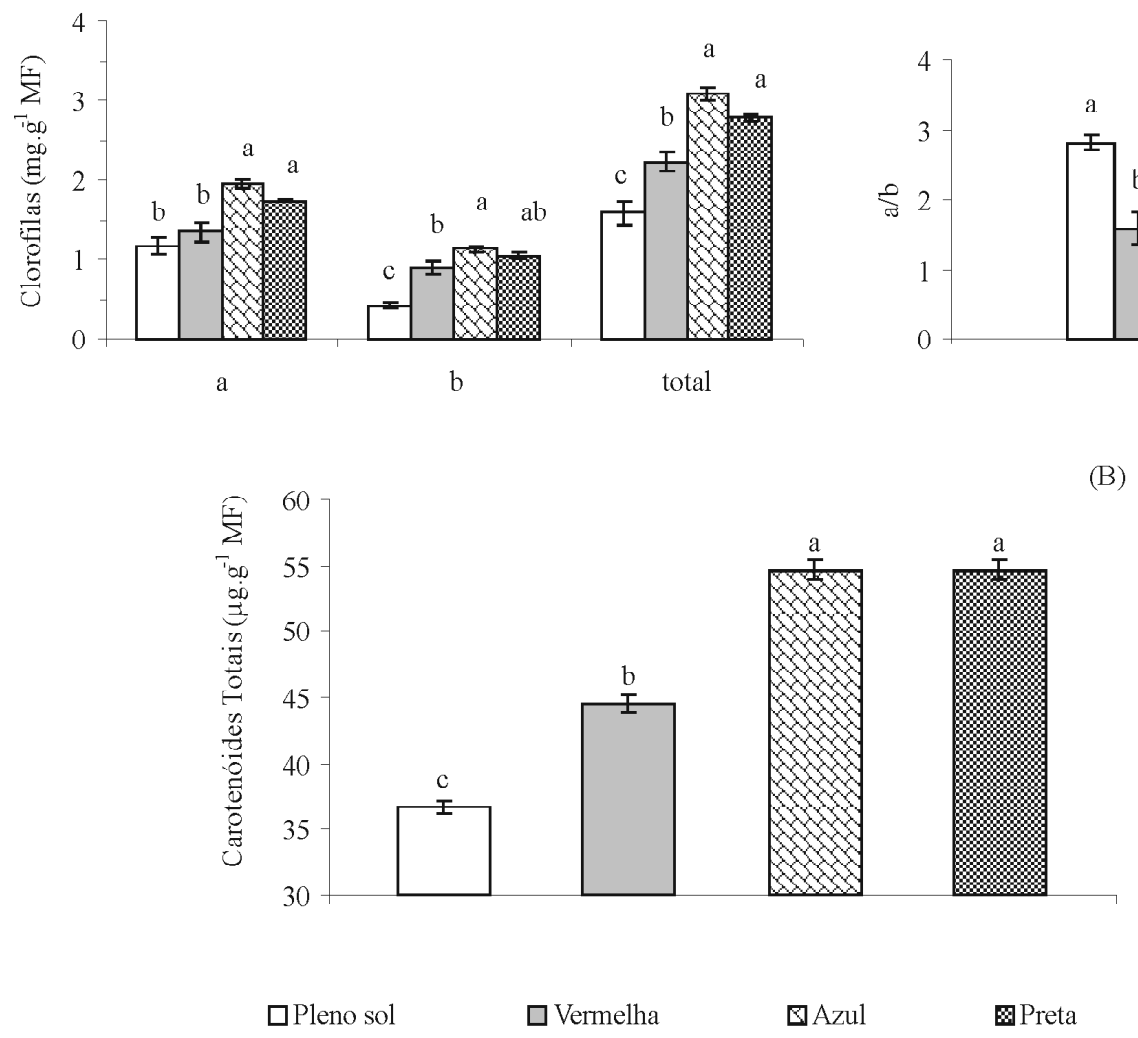

(A)

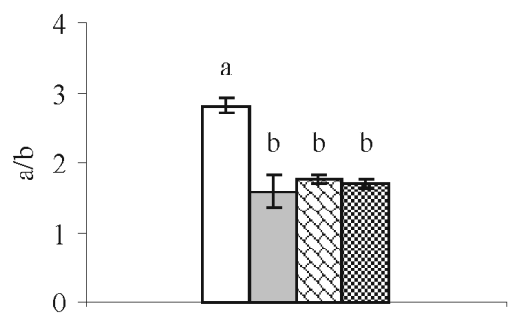

(B)

Figura 5 - Conteúdo de clorofilas a, b e total, Razão clorofila a/b (A) e conteúdo de carotenóides (B) de plantas de Catharanthus roseus cv. 'Pacifica White', submetidas ao sombreamento sob telados com malhas de diferentes cores e a pleno sol, durante 180 dias. Linhas verticais representam o erro padrão entre as médias $(\mathrm{n}=6)$. Médias seguidas da mesma letra não diferem significativamente entre si, pelo teste de Tukey, a 5\% de probabilidade.

tratamento. Desse modo, o maior conteúdo de clorofilas e carotenóides, nas folhas sob malhas azul e vermelha, pode ser relacionado ao maior conteúdo de carotenóides nesses tratamentos (FIGURA 5 B).

A maior área foliar, em detrimento de um menor conteúdo de clorofilas e carotenóides, observados para o tratamento com malha vermelha em relação aos demais, pode ter resultado em uma maior capacidade de produção de fotoassimilados, fato que pode explicar o maior teor de matéria seca de parte aérea. Assim, o comportamento dessas plantas parece não constituir apenas uma resposta mediada por fitocromos (evitação à sombra), mas uma complexa interação entre percepção e sinalização entre diversos fotorreceptores nessa condição de irradiância.

\section{CONCLUSÕES}

Plantas de $C$. roseus cv. 'Pacifica White' se adaptam melhor a ambientes sombreados, independentemente da variação espectral, uma vez que plantas cultivadas a pleno sol mostram menor matéria seca total, com baixo teor de pigmentos foliares e sinais aparentes de fotoinibição.

\section{REFERÊNCIAS BIBLIOGRÁFICAS}

ANDERSON, J. M.; CHOW, W. S.; PARK, Y. I. The grand design of photosynthesis: acclimation of the photosynthetic apparatus to environmental cues.

Photosynthesis Research, Dordrecht, v. 46, n. 1/2, p. 129-139, Nov. 1995.

ARNON, D. I. Copper enzymes in isolated chloroplasts. Polyphenoloxidase in Beta vulgaris. Plant Physiology, Minneapolis, v. 24, n. 1, p. 1-15, Jan. 1949.

BALLARÉ, C. L. et al. Photomorphogenic processes in the agricultural environment. Photochemistry and Photobiology, Oxford, v. 56, n. 5, p. 777-788, 1992.

BATSCHAUER, A. Photoreceptors of higher plants. Planta, Berlin, v. 206, n. 4, p. 479-492, Oct. 1998. 
BENINCASA, M. M. P. Análise de crescimento de plantas: noções básicas. Jaboticabal: FCAV-Unesp, 1988. $41 \mathrm{p}$.

COLON-CARMONA, A. et al. Aux/IAA proteins are phosphorylated by phytochrome in vitro. Plant Physiology, Minneapolis, v. 124, p. 1728-1738, Dec. 2000.

DIAS-FILHO, M. B. Physiological responses of two tropical weeds to shade: II leaf gas exchange and nitrogen content. Pesquisa Agropecuária Brasileira, Brasília, v. 34, n. 6, p. 953-961, jun. 1999.

DUKE, S. O.; KENYON, W. H. Effects of dimethazone (FMC 57020) on chloroplast development II: pigment synthesis and photosynthetic function in cowpea (Vigna unguiculata L.) primary leaves. Pesticide Biochemistry and Physiology, San Diego, v. 25, n. 1, p. 11-18, Feb. 1986.

EDREVA, A. Generation and scavenging of reactive oxygen species in chloroplasts: a submolecular approach. Agriculture, Ecosystems and Environment, Amsterdam, v. 106, n. 2/3, p. 119-133, Apr. 2005.

EVANS, J. R.; POORTER, H. Photosynthetic acclimation of plants to growth irradiance: the relative important of specific area and nitrogen partitioning in maximizing carbon gain. Plant Cell and Environment, Oxford, v. 24, n. 8, p. 755-767, Aug. 2001.

FRANKLIN, K. A.; WHITELAM, G. C. Phytochromes and shade-avoidance responses in plants. Annals of Botany, London, v. 96, n. 2, p. 169-175, Aug. 2005.

KASPERBAUER, M. J.; PEASLEE, D. E. Morphology and photosynthetic efficiency of tobacco leaves that receive end-of day red or far red light. Plant Physiology, Washington, v. 52, p. 440-442, 1973.

LI, S. et al. Growth responses of chrysanthemum and bell pepper transplants to photoselective plastic films. Scientia Horticulturae, Amsterdam, v. 84, n. 3, p. 215225, June 2000.

MA, T. S.; ZUAZAGA, G. Micro-Kjeldahl determination of nitrogen: a new indicator and an improved rapid method. Industrial and Engineering Chemistry, [S.l.], v. 14, n. 3, p. 280-282, 1942.
McMAHON, M. J.; KELLY, J. W. Anatomy and pigments of chrysanthemum leaves developed under spectrally selective filters. Scientia Horticulturae, Amsterdam, v. 64, n. 3, p. 203-209, Nov. 1995.

MORGAN, D. C.; SMITH, H. Simulated sunflecks have large, rapid effects on plant stem extension. Nature, London, v. 273, p. 534-536, June 1978.

OREN-SHAMIR, M. et al. Coloured shade nets can improve the yield and quality of green decorative branches of Pittosporum variegatum The Journal of Horticultural Science and Biotechnology, Asford, v. 76, n. 3, p. 353-361, May 2001.

PARKS, B. M.; FOLTA, K. M.; SPALDING, E. P. Photocontrol of stem growth. Current Opinion in Plant Biology, [S.1.], v. 4, n. 5, p. 436-440, Oct. 2001.

PONS, T. L.; BERKEL, Y. E. M. de J. van. Species-specific variation in the importance of the spectral quality gradient in canopies as a signal for photosynthetic resource partitioning. Annals of Botany, London, v. 94, n. 5, p. 725-732, Nov. 2004.

RAJAPAKSE, N. C. et al. Plant height control by photoselective filters: current status and future prospects. Horttechnology, [S.1.], v. 9, n. 4, p. 618-624, Oct./Dec. 1999.

RAJAPAKSE, N. C.; KELLY, J. C. Regulation of chrysanthemum growth by spectral filters. Journal of the American Society for Horticultural Science, Alexandria, v. 117, n. 3, p. 481-485, 1992.

SANDMAN, G.; BÖGER, P. Comparison of the bleaching activity of norfluorazon and oxyfluorfen. Weed Science, Champaign, v. 31, n. 3, p. 338-341, May 1983.

SHAHAK, Y. et al. ColorNets: a new approach for light manipulation in fruit trees. Acta Horticulturae, The Hague, v. 636, p. 609-616, 2004.

SMITH, H.; WHITELAM, G. C. The shade avoidance syndrome: multiple responses mediated by multiple phytochromes. Plant, Cell and Environment, Oxford, v. 20, p. 840-844, 1997. 